\section{CORRECTION}

View Article Online

View Journal I View Issue

\section{D) Check for updates}

Cite this: Nanoscale, 2022, 14, 3291

\section{DOI: 10.1039/d2nr90030k \\ rsc.li/nanoscale}

\title{
Correction: Metallo-boranes: a class of unconventional superhalogens defying electron counting rules
}

\author{
Huta Banjade, (D) Hong Fang (D) and Puru Jena (D) *
}

Correction for 'Metallo-boranes: a class of unconventional superhalogens defying electron counting rules' by Huta Banjade et al., Nanoscale, 2022, 14, 1767-1778, DOI: 10.1039/D1NR06929B.

The authors regret that one of the panels from Fig. 6(c) was inadvertently omitted from the original published article. The correct version of Fig. 6 and its associated caption is as displayed herein.

(a)
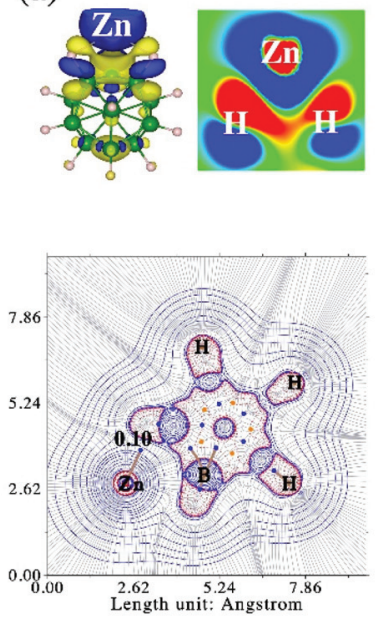

(b)
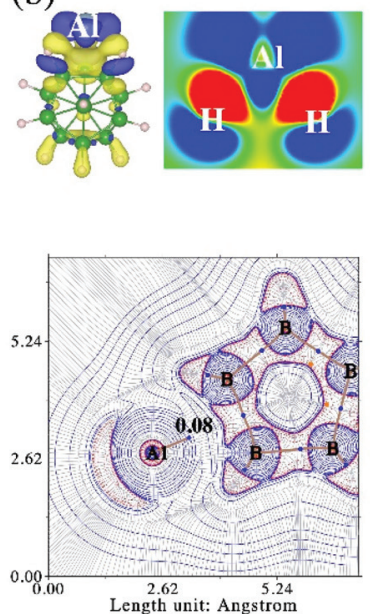

(c)

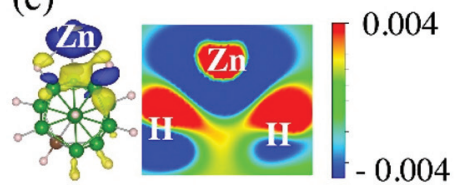

Fig. 6 Calculated CDD (top) and contour map of the Laplacian of electron density with $B C P s$ (bottom) in (a) $\mathrm{Zn}\left(\mathrm{B}_{12} \mathrm{H}_{11}\right),(\mathrm{b}) \mathrm{Al}\left(\mathrm{B}_{12} \mathrm{H}_{12}\right)$, and $(\mathrm{c}) \mathrm{Zn}$ $\left(\mathrm{CB}_{11} \mathrm{H}_{12}\right)$. 3D, 2D CDD plots along $\mathrm{Zn}-\mathrm{H}$ and $\mathrm{Al}-\mathrm{H}$ bonds are shown. In the contour plot (bottom panel), the numerical values of the Laplacian of electron density (in atomic units) are presented at corresponding BCPs.

The Royal Society of Chemistry apologises for these errors and any consequent inconvenience to authors and readers. 